\title{
ВЛИЯНИЕ НОРМИРОВАННОГО КОРМЛЕНИЯ И ФИЗИЧЕСКОЙ НАГРУЗКИ НА ФИЗИОЛОГИЧЕСКОЕ СОСТОЯНИЕ СОБАК
}

\section{E. A. Kozina}

\section{THE INFLUENCE OF RATIONED FEEDING AND PHYSICAL ACTIVITY ON PHYSIOLOGICAL STATUS OF DOGS}

Козина E.A. - канд. биол. наук, доцент каф. зо0технии и технологии переработки продуктов животноводства Красноярского государственного аграрного университета, г. Красноярск.

E-mail: kozina.e.a@mail.ru

Усnешное восстановление собак с ортопедическими проблемами в послеоперационный период возможно при нормированном кормлении и фризической нагрузке. Основные задачи исследований - изучение кормления собак в зависимости от фризиологического состояния, особенностей восстановления собак при дисплазии тазобедренного сустава (ТБС), динамики восстановления мышечной массы. В послеоперационный период резекции бедра опытным животным скармливали в составе основного рациона витаминный комплекс "Страйд», а также проводили восстановительные фризические занятия. В первый месяи начинали занятия с массажа. Далее проводили электростимуляцию мыши, затем занятия в бассейне. В течение 2-го месяца восстановления собаки занимались в бассейне, а в 3-й месяи дополнительно чередовали занятия на беговой дорожке и балансировочном оборудовании. На 4-м месяце 1 раз в неделю собаки занимались в бассейне и 2 раза на специализированном фитнес-оборудовании. Отдыхали собаки в течение 5-го месяца опытного периода, а в 6-м месяце по одному занятию в неделю проводили в бассейне и на фотнесоборудовании. В начале и коние опыта у собак брали промеры. За 6 месяцев объем мышечной массы увеличился значительно, а масса тела - на 2 ке. Одна из собак опытной группы через 8 месяцев после операции участвовала в выставке собак, где оценена на отлично, отмечен хороший толчок задних конечностей. По окончании опыта собаки контрольной группы,
Kozina E.A. - Cand. Biol. Sci., Assoc. Prof., Chair of Animal Breeding and Technology of Livestock Products Processing, Krasnoyarsk.

E-mail: kozina.e.a@mail.ru

которые получали только основной рацион, хромали и у них конечность - с непрямолинейными движениями, у животных опытной группы хромота не заметна, движения прямолинейные. Таким образом, применение витаминного комплекса "Страйд» и восстановительных занятий является целесообразным.

Ключевые слова: собака, корм, витаминный комплекс, промеры, восстановление, нормированное кормление, дисплазия тазобедренного сустава, мышечная масса, бассейн, фотнес-оборудование.

Successful recovering of dogs with orthopedic problems during post-operative period is possible with rationed feeding and physical activity. The main goals of the research include the studying of dogs' feeding depending on their physiological status; of peculiar features of dogs' recovering with hip dysplasia (HD); of muscle recovery dynamics. During post-operative period after hip resection, experimental animals were fed with vitamin complex "Straid" within the main ration and the rehabilitation exercises were made. During the 1-st month the treatment was started with massage. Then the muscles' electrostimulation was made, and further - exercises in the pool. During the 2-nd month, the recovering of the dog took place in the pool, and in the third month, the exercises on canine treadmill and balancing equipment in sequence were introduced. At the 4-th month, the dogs exercised in the pool once a week and two times on specialized fitness equipment. During the 5-th month, the animals had a 
rest, and at the 6-th month, they had one exercise a week in the pool and one - on fitness equipment. At the beginning and at the end of the research the dogs were tested. During six months the muscle bulk increased greatly and the body mass - by $2 \mathrm{~kg}$. One of the dogs from experimental group participated in the exhibition of dogs in 8 months after the operation where it had been given the highest mark, a good impulse of hind limbs was noticed. After the research, the dogs, which received only the main ration, were lame and their limbs did not have straightline motion, while the animals of experimental group were not visibly lame and had straight-line motion of the limbs. Therefore, the application of vitamin complex "Straid" and the rehabilitation exercises are reasonable.

Keywords: dog, feed, vitamin complex, tests, recovering, rationed feeding, hip dysplasia, muscle bulk, pool, fitness equipment.

Введение. Обоснованием исследований послужила необходимость в научном подходе к методике тренировок с собаками с учетом оптимизации условий содержания и кормления, а также возраста собак с ортопедическими проблемами. В связи с тем, что в разведении собак не ведется подбор пар по состоянию здоровья, в России очень много собак с ортопедическими проблемами [1]. Как жить с такими проблемами, большинство владельцев не знает.
Цель исследований. Изучить влияние нормированного кормления и физической нагрузки на физиологическое состояние собак.

Задачи исследований: изучить кормление собак в зависимости от физиологического состояния; особенности восстановления собак при дисплазии тазобедренного сустава (ТБС); динамику восстановления мышечной массы в послеоперационный период.

Материал, объекты и методы исследований. Объектом исследования стали кобели породы ротвейлер. Данные фиксировались в индивидуальной карточке каждой собаки, где записывались все профилактические мероприятия и схемы тренировок. Применялась методика измерения животных, их взвешивания, кроме того, проводилось наблюдение за их состоянием.

Научно-хозяйственный опыт был проведен в ООО «Дог Шоу Центр» (ДШЦ) г. Красноярска. Было сформировано две группы собак по принципу пар-аналогов [2] по 4 головы в каждой (табл. 1). Проводилось наблюдение над собаками породы ротвейлер с проблемами в тазобедренном суставе [1]. Наблюдались собаки с дисплазией тазобедренного сустава со стадией $D, E$, прооперированные в ветеринарной клинике [3]. Часть из них была отправлена на консультацию в ДШЦு. Научные исследования продолжались 6 месяцев.

\section{Схема опыта}

Таблица 1

\begin{tabular}{|l|c|c|c|}
\hline \multicolumn{1}{|c|}{ Группа } & $\begin{array}{c}\text { Количество } \\
\text { голов }\end{array}$ & Условия кормления & Изучаемые показатели \\
\hline 1 - контрольная & 4 & Основной рацион (ОР) & $\begin{array}{c}\text { 1.Нормированное кормление. } \\
\text { 2- Физиологическое состояние. } \\
2 \text { - опытная }\end{array}$ \\
\hline
\end{tabular}

Основной рацион включает в себя готовый корм Hills Prescription Diet JID. Животные опытной группы к основному рациону дополнительно получали витаминную добавку «Страйд», а также с ними проводилась восстановительная физическая терапия.

Все собаки поставлены на опыт с 10-го дня после операции. На начало исследований швы у собак были уже сняты. у собак контрольной группы наблюдается мышечная атрофрия. В опытной группе у двух собак наблюдалась мышечная атрофия, у одной - незначительная атрофия, у четвертой различался объем мышечной массы на лапах.

У всех собак терапия начиналась с массажа (2 занятия), это помогло узнать инструктору о болевом синдроме у собаки и о восстановлении рефрлексов на прооперированной конечности. 
Кобели с мышечной атрофрией направлены для восстановления на электростимуляцию мышц в течение 10 дней, затем на занятия в бассейне. На втором месяце восстановительной терапии занятия проходили в бассейне. В течение третьего месяца проводились занятия в бассейне, а также чередовались занятия на специализированной беговой дорожке и балансировочном оборудовании. Четвертый месяц включал занятия в бассейне раз в неделю, 2 занятия на специализированном фитнесоборудовании. Пятый месяц - отдых; шестой месяц - 1 занятие в бассейне, 1 занятие на специализированном фитнес-оборудовании.

У остальных третье занятие в течение первого месяца проводились только в бассейне. На втором месяце восстановительной терапии чередовались занятия в бассейне и на специализированной беговой дорожке и балансировочном оборудовании [4]. В течение третьего месяца раз в неделю проводились занятия в бассейне, 2 занятия на специализированном фитнесоборудовании. На протяжении четвертого месяца - отдых; пятого - по одному занятию в бассейне и на специализированном фитнесоборудовании. В следующий месяц отдых.

Электростимуляция мышц проводилась у собак аппаратом «Стимул-1», который используют для комплексного лечения травм и болезней опорно-двигательного аппарата, разнообразных параличей, порезов, для укрепления мышц, устранения жировых слоев, при усиленных фризических нагрузках.

В начале занятия собакам делался интенсивный массаж в течение 15 минут, потом одевался стимулятор на прооперированную конечность: один электрод на бедро, второй на голень, давался переменный ток с 5-секундными паузами, стимуляция длилась в течение 30 минут. После стимуляции проводился расслабляющий массаж в течение 15 минут.

В отдельном помещении (100 кв. м) находился бассейн 4×2 метра - каркасного вида, ванна 170 см, лестница в бассейн для подъема и спуска средних и крупных пород собак, с кварцевой лампой.
Перед купанием собака обрабатывается специальным шампунем, затем хлоргексидином, также можно использовать шампунь с хлоргексидином, собака привита, обработана от глистов. Кроме того, перед купанием проходит обследование у дерматолога. В воде инструктор с собакой занимается 30 минут, затем пес отдыхает. В бассейне для каждой собаки подбираются разные занятия. Плавание в течение 5 минут равноценно бегу на 7 км без нагрузки на суставы и позвоночник. Перед бассейном нельзя кормить собаку. Это чревато заворотом желудка, что представляет огромную опасность.

Вместе с занятиями в бассейне у собак опытной группы проводились занятия в фритнескабинете на специализированном оборудовании.

В помещении фитнес-зоны проходят тренировки по реабилитации, кабинет оборудован беговой дорожкой, физиороллами (балансировочные тренажеры), кавалетти, аппликатором Кузнецова, роликовой массажной доской, батутом. Комната изолирована, чтобы на занятиях собаку никто не отвлекал.

Длина бегового полотна достаточная, и собака может полностью выбрасывать лапу. Электрическая беговая дорожка может позволить развить псу скорость до 18 км/ч. Инструктор помогает собаке освоить дорожку.

Во время тренировки собаку нельзя оставлять одну. Окно на улицу обязательно должно быть открыто.

Длительность занятия фитнесом 60 минут, из них по 10 минут массаж в начале занятия - разогревающий, в конце занятия - расслабляющий. На протяжении всех занятий контролировалось общее состояние и настроение собак.

Правильное и умеренное кормление собаки в послеоперационный период - один из главных факторов на быстрое восстановление $[5,6]$. Собаку переводят на специализированный корм Hills Prescription Diet JID (табл. 2) плавно, чтобы не расстроился желудочно-кишечный тракт [7].

Норма суточного рациона зависит от массы тела собаки (табл. 3). 
Состав и питательная ценность основного рациона на 1 кг корма

Таблица 2

\begin{tabular}{|l|c|l|c|}
\hline \multicolumn{1}{|c|}{ Корм, вещество } & Содержание & \multicolumn{1}{|c|}{ Корм } & Содержание \\
\hline Злаки & $*$ & Калий, \% & 0,71 \\
\hline Курица, \% & 10 & Магний, \% & 0,15 \\
\hline Экстракты растительного белка & $*$ & Витамин A, ME & 9180 \\
\hline Жиры & $*$ & Витамин D, ME & 705 \\
\hline Моллюски и ракообразные & $*$ & Витамин Е, мг & 600 \\
\hline Яйцо и его производные & $*$ & Витамин С, мг & 90 \\
\hline Минералы & $*$ & Бета-каротин, мг & 1,5 \\
\hline \multirow{2}{*}{ Белок, \% } & \multirow{2}{*}{ *,6 } & Глюкозамин, мг & 608 \\
\cline { 2 - 4 } & & Хондроитин, мг & 323 \\
\hline Жир, \% & 14,7 & L-каротин, мг & 305 \\
\hline Омега-3, \% & 3,3 & Железо, мг & 73,4 \\
\hline ЕРА, \% & 0,39 & Иод, мг & 1,1 \\
\hline Клетчатка, \% & 5,3 & Медь, мг & 7,2 \\
\hline Зола, \% & 4,4 & Марганец, мг & 7,6 \\
\hline Кальций, \% & 0,61 & Цинк, мг & 152 \\
\hline Фосфрор, \% & 0,48 & Селен, мг & 0,2 \\
\hline Натрий, \% & 0,23 & Энергетическая ценность, ккал & 362 \\
\hline
\end{tabular}

* Отсутствуют данные по количеству в составе.

Таблица 3

Количество корма в сутки, г

\begin{tabular}{|c|c|c|c|}
\hline Масса тела, кг & Количество корма & Масса тела, кг & Количество корма \\
\hline 2,5 & $50-70$ & 30 & $335-460$ \\
\hline 5 & $85-120$ & 40 & $415-570$ \\
\hline 10 & $145-205$ & 50 & $500-630$ \\
\hline 20 & $245-340$ & & \\
\hline
\end{tabular}

Kopм Hill's Prescription Diet j/d обеспечивает диетическое питание с клинически доказанной эффективностью для поддержания здоровья собак при различных заболеваниях, диетотерапию при заболеваниях суставов, улучшает подвижность собаки $[8,9]$. Содержит высокий уровень ЕРА (эйкозапентаеновой кислоты), общих омега-3 жирных кислот, глюкозамина и хондроитин сульфата; сохраняет здоровье хряща, поддерживая его метаболизм; помогает прервать цикл остеоартрита и является альтернативой применению добавок глюкозамина и хондроитин сульфата [4].

Животным опытной группы был добавлен к основному рациону при тщательном перемешивании витаминный комплекс «Страйд» в течение 4 месяцев по 10 г в сутки. «Страйд» является высокоэфффективным витаминным комплексом, относящимся к новому поколению хондропротекторов, предназначенным для профилак- 
тики и лечения воспалительных и дегенеративных заболеваний суставов у собак, содержит в 10 г действующего вещества: 2000 мг метилсульфранилметана (МСM), 1080 мг глюкозамина гидрохлорида, 240 мг хондроитина сульфрата, 76 мг марганца сульфрата, 48 мг витамина С.

«Страйд» смешивали с кормом крупным собакам (более 30 кг) в количестве 15 г в сутки; если прием препарата более двух месяцев, то дозировка 10 г в сутки. «Страйд» необходимо принимать минимум 30 дней. Затем, в зависимости от результата, продолжают давать витаминный комплекс в такой же дозировке или уменьшают дозу.

Питательность суточного рациона представлена в таблице 4.

Таблица 4

\section{Питательность суточного рациона}

\begin{tabular}{|c|c|c|c|c|c|}
\hline \multirow{2}{*}{ Показатель } & \multicolumn{2}{|c|}{ Группа } & \multirow{2}{*}{ Показатель } & \multicolumn{2}{|c|}{ Группа } \\
\hline & контрольная & опытная & & контрольная & опытная \\
\hline $\begin{array}{l}\text { Обменная энергия, ОЭ, } \\
\text { ккал }\end{array}$ & 1991 & 1991 & Витамин Е, мг & 330 & 330 \\
\hline Белок, г & 100,65 & 100,65 & Витамин C, мг & 38,5 & 86,5 \\
\hline Жир, г & 82,5 & 82,5 & Бета-каротин, мг & 0,83 & 0,83 \\
\hline Жирные кислоты, г & 18,5 & 18,5 & Глюкозамин, мг & 211,75 & 1291,75 \\
\hline EPA, г & 2,15 & 2,15 & Хондроитина сульфрат, мг & 310,75 & 550,75 \\
\hline Клетчатка, г & 24,75 & 24,75 & L-каротин, мг & 304 & 304 \\
\hline Зола, г & 23,1 & 23,1 & Железо, мг & 242 & 242 \\
\hline Кальций, г & 3,19 & 3,19 & Йод, мг & 3,6 & 3,6 \\
\hline Фоссрор, г & 2,81 & 2,81 & Медь, мг & 6,66 & 6,66 \\
\hline Натрий, г & 0,88 & 0,88 & Марганец, мг & 10,7 & 86,7 \\
\hline Калий, г & 3,91 & 3,91 & Цинк, мг & 206 & 206 \\
\hline Магний, г & 0,83 & 0,83 & Селен, мг & 0,5 & 0,5 \\
\hline Витамин A, ME & 5720 & 5720 & $\begin{array}{l}\text { МСМ метил- } \\
\text { сульфранилметан, мг }\end{array}$ & - & 2000 \\
\hline Витамин D, ME & 242 & 242 & & & \\
\hline
\end{tabular}

Корм измерялся специализированным фирменным мерным стаканом, «Страйд» - специальной мерной ложкой.

В рационе опытной группы за счет включения витаминного комплекса «Страйд» увеличилось содержания витамина С, глюкозамина, хондроитина, марганца, обогатился рацион МСM (метильфанилметан), так как в рационе контрольной группы он отсутствует.

Для изучения динамики восстановления мышечной массы в послеоперационный период у собак до операции и по окончании опыта брали промеры мерной лентой, рост в холке измерялся ростомером, масса тела измерялась на весах товарных МИДЛ МП 60 ВДА Ф-2 (20;450х600) «Гулливер 12». При измерении бедра лентой обмеряют самое объемное место на нем. Голень обмеряют в 2 см от коленного сустава.

Биометрическая обработка результатов опыта проводилась с использованием персонального компьютера в программе «Microsoft Excel» c расчетом средних арифметических показателей и ее ошибки (M $\pm \mathrm{m})$. Критерий достоверности (P) определялся по методике Н.А. Плохинского (1969) [10].

Результаты исследований и их обсуждение. Промеры подопытных животных представлены в таблице 5. 
Масса тела и промеры собак

\begin{tabular}{|c|c|c|c|c|}
\hline \multirow{4}{*}{ Промеры } & \multicolumn{4}{|c|}{ Группа } \\
\hline & \multicolumn{2}{|c|}{ контрольная } & \multicolumn{2}{|c|}{ опытная } \\
\hline & \multicolumn{4}{|c|}{ Период } \\
\hline & до операции & после операции & до операции & после операции \\
\hline Масса тела, кг & $49 \pm 2,55$ & $50,5 \pm 2,47$ & $52,75 \pm 4,37$ & $54,75 \pm 4,48$ \\
\hline Высота в холке, см & $64,5 \pm 0,50$ & $64,75 \pm 0,48$ & $65,5 \pm 1,55$ & $66,5 \pm 1,44$ \\
\hline Обхват грудной клетки, см & $90,75 \pm 1,70$ & $91 \pm 1,47$ & $93,88 \pm 4,75$ & $96 \pm 4,38$ \\
\hline Обхват правого бедра, см & $39 \pm 0,71$ & $40,63 \pm 0,85$ & $44,5 \pm 2,22$ & $48,63 \pm 1,60$ \\
\hline Обхват левого бедра, см & $37,63 \pm 1,86$ & $39,88 \pm 1,88$ & $42,38 \pm 2,70$ & $48,25 \pm 1,89$ \\
\hline Обхват правой голени, см & $23,88 \pm 0,43$ & $24,5 \pm 0,50$ & $24,75 \pm 1,20$ & $26 \pm 0,71$ \\
\hline Обхват левой голени, см & $21,25 \pm 0,43$ & $22,63 \pm 0,38^{*}$ & $23,38 \pm 0,72$ & $25,88 \pm 0,55^{\star}$ \\
\hline Обхват правого плеча, см & $31 \pm 1,00$ & $32,5 \pm 0,96$ & $34,5 \pm 1,26$ & $36,25 \pm 1,03$ \\
\hline Обхват левого плеча, см & $31,13 \pm 1,07$ & $32,5 \pm 0,87$ & $35,13 \pm 1,25$ & $36,5 \pm 1,02$ \\
\hline
\end{tabular}

Примечание. Здесь и далее показана достоверность разницы по отношению к аналогичному показателю сравниваемых групп: *P>0,95; ** $\mathrm{P}>0,99 ;{ }^{* * *} \mathrm{P}>0,999$.

Анализируя данные таблицы, можно сделать вывод, что у собак контрольной группы спустя 6 месяцев отмечается незначительный рост мышечной массы. А у собак опытной группы по окончании курса промеры конечностей практически не отличаются, разница между здоровой и прооперированной конечностью в среднем 0,4 см, а у контрольной группы 1,5-2 см. Левая голень у собак опытной группы восстановилась на 2,5 см ( $\mathrm{P}>0,95)$, что больше, чем у опытной, на 1,12 см. Отмечается динамика в росте мышечной массы в обхвате плеча: у контрольной он больше на 1 см; у опытной - на 1,5-2 cм. Это говорит о том, что у опытной группы за 6 месяцев объем мышечной массы значительно увеличился по сравнению с контрольной группой. Обхват грудной клетки у животных опытной группы был больше на 1,87 см по сравнению с контрольной.

Изменения за шесть месяцев массы тела: в среднем у собак контрольной группы она увеличилась на 1,5 кг, а у опытной группы - на 2 кг.
При том что потребление корма в обеих группах одинаковое.

Изменения роста в холке в двух группах произошли только потому, что в этих группах находились собаки с незакрытыми ростовыми зонами. Изменения в среднем по группам составили: в контрольной - 0,25 см, опытной - 1 см.

Исходя из данных, можно сделать вывод, что в опытной группе увеличение мышечной массы выше, чем в контрольной. Это говорит о том, что опыт дал положительные результаты.

Одна из собак опытной группы Дан спустя 8 месяцев после операции участвовала в выставке собак [11], где получил наивысшую оценку отлично, победитель класса, сертификат САС (кандидат в национальные чемпионы красоты), на выставке судья отметил хороший толчок задних конечностей. Это говорит о том, что собака восстановилась на $100 \%$. Состояние прооперированной конечности у подопытных животных представлено в таблице 6. 


\section{Состояние оперированной конечности}

\begin{tabular}{|c|c|c|}
\hline $\begin{array}{c}\text { Период после } \\
\text { операции, дн. }\end{array}$ & Контрольная группа & Опытная группа \\
\hline 30 & $\begin{array}{c}\text { Мышечная атрофия, не наступают на } \\
\text { конечность }\end{array}$ & Хромота, приступают на конечность \\
\hline 60 & $\begin{array}{c}\text { Мышечная атрофия, приступают на } \\
\text { конечность }\end{array}$ & $\begin{array}{c}\text { Хорошо опираются на конечность, } \\
\text { хромота }\end{array}$ \\
\hline 90 & - & $\begin{array}{c}\text { Незначительная хромота, движения } \\
\text { практически прямолинейные }\end{array}$ \\
\hline 120 & $\begin{array}{c}\text { Мышечная атрофия, заметна сильная } \\
\text { хромота }\end{array}$ & $\begin{array}{c}\text { Незначительная хромота, движения } \\
\text { практически прямолинейные }\end{array}$ \\
\hline 150 & - & - \\
\hline 180 & $\begin{array}{c}\text { Хромота, конечность с } \\
\text { непрямолинейными движениями }\end{array}$ & $\begin{array}{c}\text { Хромота не заметна, движения } \\
\text { прямолинейные }\end{array}$ \\
\hline
\end{tabular}

По данным таблицы 6 можно сделать вывод, что собаки контрольной группы очень медленно восстанавливались и полностью не восстановились. Тогда как собаки опытной группы восстанавливались намного быстрее, и в конце опыта конечности их практически не отличались, что говорит о правильно составленной программе восстановления.

У собак контрольной группы в конце опыта отмечается неполное восстановление: 50 \% питомцев перегрузили здоровую конечность, а через 6-8 месяцев были отправлены на операцию другой конечности.

У животных опытной группы качество жизни заметно улучшилось, по истечении восстановительного курса практически не заметно, на какой из конечностей была проведена операция.

Заключение. Нормированное кормление собак с включением в рацион витаминного комплекса «Страйд» в количестве 10 г на голову в сутки и восстановительные занятия (применение массажа, электростимуляция мышц, бассейн, использование беговой дорожки и балансировочного оборудования) способствовали росту мышечной массы, исчезновению хромоты и прямолинейному движению прооперированной конечности при дисплазии ТБС, которая практически не отличалась от второй конечности у собак.

\section{Литература}

1. Давыдов В.Б. О возрасте диагностирования и симптомах дисплазии тазобедренных суставов у собак // Друг. - 2003. - № 6. С. $15-17$.

2. Овсянников А.И. Основы опытного дела. М.: Колос, 1976. - 302 с.

3. Донская Т.К., Нарусбаева М.А. Болезни собак. - М.: Эксмо, 2003. - С. 386-390.

4. Савин А., Липин А., Зинченко Е. Ветеринарный справочник традиционных и нетрадиционных методов лечения собак. - М.: Центр-полиграф, 2002. - С. 312-315.

5. Козина Е.А., Полева Т.А. Нормированное кормление животных и птицы. Ч. ІІ. Кормление моногастричных животных, птицы, пушных зверей, собак и кошек: учеб. пособие / Краснояр. гос. аграр. ун-т. - Красноярск, 2012. - С. 184-204, 258-269.

6. Козина Е.A. Кормление мелких домашних животных: учеб. пособие / Краснояр. гос. аграр. ун-т. - Красноярск, 2007. - С. 69-88.

7. Эйман Ф., Гражан Д., Бакку Х. [и др.]. Немецкая овчарка: энциклопедия. - М.: Жизнь, 2004. - С. 87-329.

8. Богданова И.Б. Кормление собак // Друг. 2013. - № 12. - C. 5-6.

9. Горшков В.В. Нормы кормления // Друг. 2004. - № 27. - C. 18. 
10. Плохинский Н.А. Биометрия. - М.: Изд-во МГУ, 1970. - 367 с.

11. Гусев В.Г., Гусева Е.С. Кинология: пособие для экспертов и владельцев племенных собак. - М.: Аквариум, 2006. - С. 205.

\section{Literatura}

1. Davydov V.B. O vozraste diagnostirovanija i simptomah displazii tazobedrennyh sustavov u sobak // Drug. - 2003. - № 6. - S. 15-17.

2. Ovsjannikov A.I. Osnovy opytnogo dela. - M.: Kolos, 1976. - 302 c.

3. Donskaja T.K., Narusbaeva M.A. Bolezni sobak. - M.: Jeksmo, 2003. - S. 386-390.

4. Savin A., Lipin A., Zinchenko E. Veterinarnyj spravochnik tradicionnyh i netradicionnyh metodov lechenija sobak. - M.: Centr-poligraf, 2002. - S. 312-315.

5. Kozina E.A., Poleva T.A. Normirovannoe kormlenie zhivotnyh i pticy. Ch. II. Kormlenie monogastrichnyh zhivotnyh, pticy, pushnyh zverej, sobak i koshek: ucheb. posobie / Krasnojar. gos. agrar. un-t. - Krasnojarsk, 2012. - S. 184-204, 258-269.

6. Kozina E.A. Kormlenie melkih domashnih zhivotnyh: ucheb. posobie / Krasnojar. gos. agrar. un-t. - Krasnojarsk, 2007. - S. 69-88.

7. Jejman F., Grazhan D., Bakku H. [i dr.]. Nemeckaja ovcharka: jenciklopedija. - M.: Zhizn', 2004. - S. 87-329.

8. Bogdanova I.B. Kormlenie sobak // Drug. 2013. - № 12. - S. 5-6.

9. Gorshkov V.V. Normy kormlenija // Drug. 2004. - № 27. - S. 18.

10. Plohinskij N.A. Biometrija. - M.: Izd-vo MGU, 1970. - $367 \mathrm{~s}$.

11. Gusev V.G., Guseva E.S. Kinologija: posobie dlja jekspertov i vladel'cev plemennyh sobak. - M.: Akvarium, 2006. - S. 205. 